\title{
Balkanologie
}

Balkanologie Revue d'études pluridisciplinaires

Vol. II, nº 2 | 1998

Volume II Numéro 2

\section{Goati (Vladimir), ed., Challenges of Parliamentarism : The Case of Serbia in the Early Nineties}

Belgrade : Institute of Social Sciences, 1995, 328 p.

Yves Tomić

\section{CpenEdition}

\section{Journals}

Édition électronique

URL : http://journals.openedition.org/balkanologie/272

DOI : 10.4000/balkanologie. 272

ISSN : 1965-0582

Éditeur

Association française d'études sur les Balkans (Afebalk)

Édition imprimée

Date de publication : 1 décembre 1998

ISSN : 1279-7952

\section{Référence électronique}

Yves Tomić, "Goati (Vladimir), ed., Challenges of Parliamentarism: The Case of Serbia in the Early

Nineties », Balkanologie [En ligne], Vol. II, n² 2 | 1998, mis en ligne le 03 juin 2008, consulté le 17

décembre 2020. URL : http://journals.openedition.org/balkanologie/272 ; DOI : https://doi.org/ 10.4000/balkanologie.272

Ce document a été généré automatiquement le 17 décembre 2020.

(C) Tous droits réservés 


\section{Goati (Vladimir), ed., Challenges of Parliamentarism: The Case of Serbia in the Early Nineties}

Belgrade : Institute of Social Sciences, 1995, 328 p.

\section{Yves Tomić}

\section{RÉFÉRENCE}

Goati (Vladimir), ed., Challenges of Parliamentarism : The Case of Serbia in the Early Nineties, Belgrade : Institute of Social Sciences, 1995, $328 \mathrm{p}$.

1 Cet ouvrage est un recueil d'articles concernant les développements politiques en Serbie au début des années 1990. Il est le fruit d'un projet de recherche portant le titre : «Le développement du parlementarisme en Europe de l'Est et en Yougoslavie ». Peu d'études ont été publiées dans les langues occidentales sur l'évolution politique de la Serbie depuis les changements profonds de 1989-1990 en Europe centrale, orientale et du sud-est. Aussi, ce livre contenant des traductions en anglais de travaux déjà publiés en serbe est il appréciable pour la masse de données qu'il apporte au lecteur occidental.

2 Vladimir Goati relève les particularités de la vie politique serbe depuis 1989: la continuité au pouvoir de l'ancienne Ligue des communistes de Serbie, rebaptisée Parti socialiste, l'antagonisme âpre entre le Parti gouvernant et l'opposition, l'éclatement de la guerre civile yougoslave au moment de l'établissement du nouveau système politique. Du fait de la guerre et des sanctions internationales, le processus de consolidation de la démocratie s'est réalisée dans des conditions économiques et sociales plus difficiles que dans les autres pays de la région. Slobodan Antonić étudie la place et le rôle du Parlement : il note que la constitution adoptée en septembre 1990 limite significativement le pouvoir politique du Parlement. et accorde plus de pouvoir au Président que dans n'importe quel autre pays est-européen. Le Parti socialiste domine le Parlement et n'a jamais engagé de dialogue avec l'opposition dans le cadre de 
la préparation et de l'adoption des lois. Le gouvernement n'est jamais parvenu à devenir un facteur politique indépendant de la vie parlementaire. Contrairement aux autres pays en transition où le Parlement joue un rôle important face au gouvernement, le Parlement de Serbie a été marginalisé dans le processus de décision politique.

3 L'ouvrage aborde, par ailleurs, les questions du choix politique en fonction des appartenances sociales, de l'orientation des valeurs des électeurs, du rôle des minorités nationales dans le processus électoral, des campagnes électorales, du rôle des médias, du système électoral.

4 En appendice, le lecteur pourra trouver les résultats des élections de 1990, 1992 et 1993 ainsi que des extraits des programmes des principaux partis politiques : Parti socialiste de Serbie (SPS), Mouvement serbe du renouveau (SPO), Nouvelle démocratie (ND), Alliance civique de Serbie (GSS), Parti radical serbe (SRS), Parti démocrate (DS), Parti démocrate de Serbie (DSS).

\section{AUTEUR}

\section{YVES TOMIĆ}

Vladimir Goati 